\title{
Clinical Trials in Portugal: How Can we Improve?
}

\section{Ensaios Clínicos em Portugal: Como Podemos Melhorar?}

Marta CARVALHO ${ }^{1,2}$, Rita CUNHA DE EÇA ${ }^{3}$, Isabel GOMES ${ }^{4}$, Mónica GONÇALVES ${ }^{5}$, Ana LOPES ${ }^{6}$, Dina LOPES ${ }^{7}$, Joana MAIA ${ }^{8}$, Ana Marta OLIVEIRA ${ }^{9}$, Ana NORONHA ${ }^{10}$, Catarina Resende OLIVEIRA $\bowtie{ }^{11}$

Acta Med Port 2021 Feb;34(2):80-83 - https://doi.org/10.20344/amp.15155

Keywords: Clinical Trials as Topic; Portugal

Palavras-chave: Ensaios Clínicos; Portugal

\section{INTRODUCTION}

Clinical trials (CTs) are fundamental in advancing knowledge and improving healthcare, contributing to the development and marketing of innovative therapies. ${ }^{1}$ In Portugal, between 2011 - 2017, the number of authorized CTs has increased (87 to 127), though never reaching the number observed in 2006 (147 CTs). In 2017, the number of submitted CTs per one million inhabitants was 13.3 , with phase three trials continuing to be the most common. ${ }^{1}$ The economic impact of CTs in Portugal in 2017 was approximately 87 million euros, meaning that for each euro invested in CTs a return of $199 \%$ to the Portuguese economy was obtained.

Although Portugal has seen a positive evolution in CTs, compared with other European countries of similar size, the country still has the lowest number of recruited participants per million inhabitants, showing significant potential for growth.

Despite the recognized benefits of clinical research, some barriers remain to the implementation of CTs in Portugal, such as reduced patient referral due to limited involvement of general practitioners in clinical research, limited total number of clinical investigators with dedicated time to conduct research, increased complexity of regulations and CTs contracts, and lack of local supportive infrastructures. ${ }^{2}$

This perspective paper aims to highlight study centers' strengths and propose strategies that will promote the country's attractiveness and competitiveness for CTs.

\section{Clinical research units (CRU) organization}

The creation of structured CRUs is an effective mechanism to conduct research ${ }^{3}$ since they are centers of competence established to assist and centralize all stages of a clinical study: concept (feasibility), development (approval), setup (initiation), conduct (until last patient, last visit), and completion (publishing). ${ }^{2}$

Thus, it is crucial to centralize clinical trials in CRUs. Effective team interaction and communication are best practice efforts to conduct CTs, and CRUs can develop effective communication, processes and tools to improve the whole process. The sharing of knowledge and resources within an institution allows this approach to become cost-effective. ${ }^{3}$

A dedicated staff is one of the most important, yet expensive, component of a research program. ${ }^{4}$ They should be selected based on their experience in specific fields, should be trained according to the most recent standards and requirements of regulators, sponsors and other partners in the clinical research field, as well as having good mentoring skills and a track record of success.

Most Portuguese CRUs have key performance indicators (KPIs). However, some less mature CRUs are in the process of defining the KPIs they feel appropriate to monitor.

The nature and type of KPIs varies among different $\mathrm{CRUs}$, and include various parameters, from time required to answer feasibility assessment questions, to contract revision timelines, time to negotiate and sign financial contracts and to include the first participant, number of participants enrolled, recruitment rates, and start and end dates of CTs. Internal dissemination of KPI outcomes within the Hospital is extremely important since it raises awareness of the CRU's benefits and achievements. Sharing these results from an external perspective is also valuable as a strategy to attract commercial sponsors to consider the site for new upcoming trials. Table 1 summarizes the strengths of and recommendations for Portuguese CRUs.

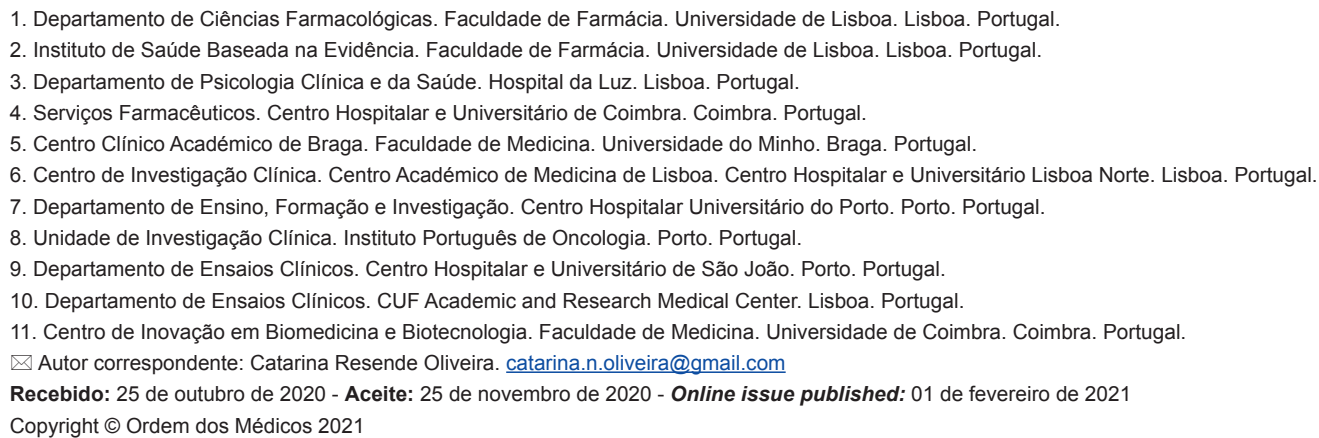




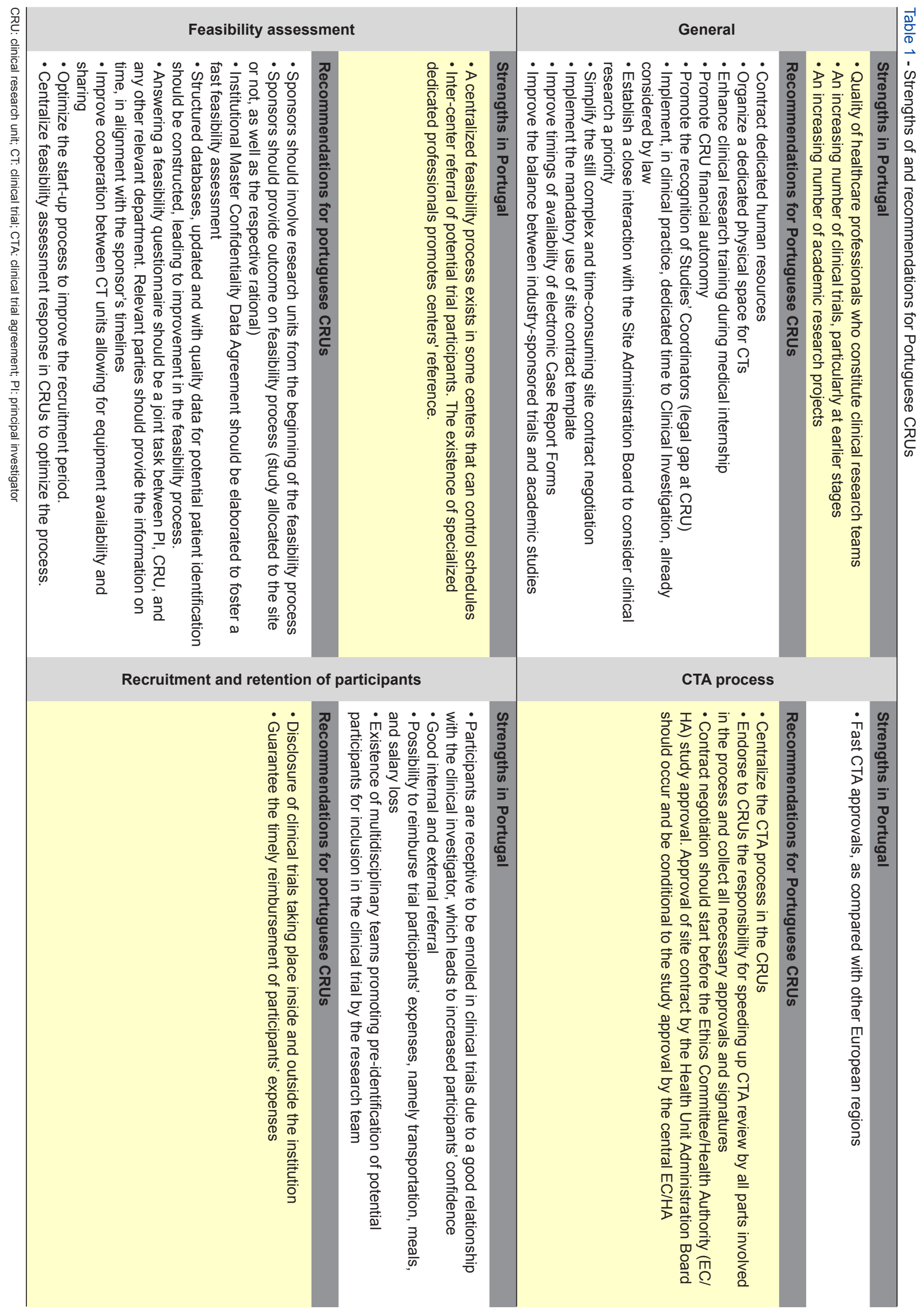




\section{Start-up process}

The clinical trial agreement (CTA) is a legally binding agreement that manages the relationship between the sponsor and the institution that will enrol CTs' participants.

A CTA should describe responsibilities, terms of collaboration, requirements for payment and reimbursement, publication and intellectual property terms, indemnification and/ or insurance contracts, study participants' injury coverage, guidelines for dispute resolution, grounds for termination of the contract, and the possibility of amending contract terms in the future.

In the majority of Portuguese centers, a mandatory site contract template is used, and contract negotiation starts before the Ethics Committee/Health Authority (EC/HA) approval. The administration board may sign the contract, conditional to the CT approval by the central EC/HA.

\section{Feasibility assessment}

Feasibility assessment is one of the first steps when conducting a clinical trial. 5,6 The feasibility questionnaire is used to assess the potential for participant recruitment in a CT site by the sponsor. ${ }^{6}$ Feasibility assessment should include investigator/site interest in a specific trial/indication and the estimated dimension of the participant population. This is crucial to determine study center/Investigator capacity and speed of participants' enrolment, as well as possible confounding factors in recruitment. Other factors may also be assessed, such as prior study center/Investigator experience in similar trials, successful participant recruitment techniques, availability of qualified site personnel and of equipment/facilities required to successfully conduct the trial, impact of study procedures on Standard of Care, and other additional sponsor requirements. ${ }^{5}$

Typically, the feasibility assessment is associated with limited protocol details and timelines, leading to increased difficulty in planning, organization and execution.

Centralization of the feasibility process in CRUs is key, as the unit has an integrated overview of CTs at the study site. Recruitment commitment should be defined considering the site's historical number of participants with the specific trial pathology, availability of clinical staff, recruitment period and any ongoing competitive studies.

\section{Study participants recruitment and retention}

Having a realistic recruitment plan, in line with the conditions existing in each center, and with the site's potential participant pool is a key determinant for the success of $\mathrm{CTs}^{7}$. Other points that should be considered when designing a recruitment plan are the number of participants meeting the required eligibility criteria, the infrastructures of the study site, and the availability of human resources.

Adequate recruitment strategies are vital for complying with the recruitment plan. Successful recruitment approaches include direct identification of participants by the research team, patient referral through inclusion of other site departments in the research team, CT advertisement (internally and externally to the study site) and a strong par- ticipant/clinician relationship. Furthermore, the participation of CRUs in multidisciplinary meetings to present the clinical trial and identify potential participants develops a competitive spirit within the research center. Monitoring the recruitment plan by research units is essential to ensure compliance. Contingency plans should be established, used and monitored.

Financial limitations of the participants and guarantee of transportation between the patient's home and study site during trial participation, as well as the reimbursement by the study sponsor of participants' travel, subsistence and loss of salary expenses, among others, are important factors to the success of participants' recruitment and retention.

The failure of retaining recruited participants can lead to potentially biased results. ${ }^{9}$ Effective retention strategies can be based on influencing participants' behaviour through incentives, reminders, or alleviating participants' burden, and should include the improvement in participant's understanding of the importance of retention ${ }^{9}$. The schedule of too many visits/procedures, a long-distance between participants' home and study site, and doubts/questions about the frequency/occurrence of adverse events are some of the reasons for participant's withdrawal.

An informed consent process with thorough explanation and information is a key retention strategy, especially if combined with reminders of the next visit/procedure, the importance of the study, good preparation of each participant's visit to give confidence to the participant, close monitoring of the participants, and ensuring timely reimbursement of the participant expenses.

\section{CONCLUSION}

This perspective paper highlights Portuguese study centers' strengths and proposes strategies to foster the country's attractiveness and competitiveness for CTs. Undoubtedly, CRUs are a focal point in the success of CT implementation at study centers, from trial feasibility to participant recruitment and retention. Researchers' motivation and information were also identified as essential factors for the success of CTs. The qualification of multidisciplinary healthcare professionals and research teams, associated with a high level of confidence and a good relationship between medical doctors and study participants, seem to be competitive factors to strengthen CTs in Portugal.

\section{ACKNOWLEDGMENTS}

The authors would like to thank, for their valuable insights regarding this paper: Teresa Almeida, Serviço de Investigação Clínica, Centro Hospitalar e Universitário do Porto, Portugal; Ana Azevedo, Centro de Epidemiologia Hospitalar, Centro Hospitalar Universitário de São João, Porto, Portugal; Luís Costa, Departamento de Oncologia Médica, Centro Hospitalar e Universitário de Lisboa Norte, Hospital de Santa Maria, Lisboa and Instituto de Medicina Molecular, Faculdade de Medicina da Universidade de Lisboa, Portugal; José Dinis, IPO Porto, Portugal; Francisca 
Leite PhD, Hospital da Luz Learning Health, Lisboa, Portugal; António Moreira, IPO Lisboa, Portugal; Anabela Possidónio, CUF Academic and Research Medical Center, Lisboa, Portugal; Nuno Sousa, School of Medicine, University of Minho, Portugal and Clinical Academic Center, Braga, Portugal.

\section{CONFLICTS OF INTERESTS}

The authors declare collaborating and receiving fees from Novartis and other pharmaceutical companies either through participation in advisory board or consultancy,

\section{REFERENCES}

1. APIFARMA P. Ensaios Clínicos em Portugal. Lisboa: Apifarma; 2019.

2. Institute of Medicine (US) Forum on Drug Discovery Development and Translation. Challenges in Clinical Research. Transforming Clinical Research in the United States: Challenges and Opportunities: Workshop Summary. Washington: National Academies Press (US); 2010. [Accessed 2019 May 11]. Available from: https://www.ncbi.nlm. nih.gov/books/NBK50888/.

3. Croghan IT, Viker SD, Limper AH, Evans TK, Cornell AR, Ebbert JO, et al. Developing a clinical trial unit to advance research in an academic institution. Contemp Clin Trials. 2015;45:270-6.

4. Baer AR, Zon R, Devine S, Lyss AP. The clinical research team. J Oncol Pract. 2011;7:188-92.

5. Rajadhyaksha V. Conducting feasibilities in clinical trials: an investment to ensure a good study. Perspect Clin Res. 2010;1:106-9.

6. Burgess LJ, Sulzer NU. Examining the clinical trial feasibility process congress symposia, clinical trial conduct, investigator-initiated trials, or grants.

\section{FUNDING}

Funding for meetings and access to all necessary bibliography was provided by Novartis Portugal. Editorial assistance was provided by Constança Coelho, from x2-Science Solutions. This assistance was funded by Novartis Portugal. Novartis Portugal had no role in the writing of the manuscript or in the decision to submit the manuscript.

and its implications for a trial site. Open Access J Clin Trials. 2011;3:514.

7. Huang GD, Bull J, Johnston McKee K, Mahon E, Harper B, Roberts JN. Clinical trials recruitment planning: a proposed framework from the Clinical Trials Transformation Initiative. Contemp Clin Trials. 2018;66:749.

8. Treweek S, Lockhart P, Pitkethly M, Cook JA, Kjeldstrøm M, Johansen $M$, et al. Methods to improve recruitment to randomised controlled trials: Cochrane systematic review and meta-analysis. BMJ Open. 2013;3:e002360.

9. Kearney A, Rosala-Hallas A, Bacon N, Daykin A, Shaw AR, Lane AJ, et al. Reducing attrition within clinical trials: The communication of retention and withdrawal within patient information leaflets. PloS One. 2018;13:e0204886 